\title{
Acute intoxication and poisoning in children: the experience of a tertiary-care hospital from 2001-2012
}

BY SALVATORE NAPODANO, DONATO RIGANTE, SILVIA PULITANÒ, MARCELLO COVINO, ALDO MANCINO, ALESSANDRO BARELLI, PAOLO MAURIZIO SOAVE, LUCA TORTOROLO

\section{Abstract}

The frequency and distribution of acute intoxications and poisoning from non-pharmacological substances in children was evaluated in this observational-descriptive study. This was done by analyzing all admissions to the Emergency Room of our University in Rome during the period $1^{\text {st }}$ January 2001 to $31^{\text {st }}$ December 2012. We found 249 patients aged 0-14 years: 147 males and 102 females. The highest incidence occurred in the first 4 years of life: $44.2 \%$ in the 1-2 year age-group. Cases were mostly related to solvents (44.6\%), natural products (17.7\%), agricultural products (12.9\%), corrosive acids and alkaline caustics (14.8\%). Most admissions occurred during the time slot 18:00 to 21:00 (23.7\%). No clinical symptoms were observed in 116 children (46.6\% of the total), and physical examination was unrevealing. The remaining 133 displayed nausea/vomiting (22\%) and pharyngeal hyperemia (18.8\%). Laboratory tests and imaging studies were only performed in selected cases. In terms of consulting requests, the Poisons Center was contacted 
156 times (62.6\% of cases), the Pediatric Intensive Care Unit 38 times (15.2\%), and the surgeon-endoscopist 18 times (7.2\%). A short period of observation and monitoring in the Emergency Room was warranted in 106 children (42.5\%). Gastroprotective drugs were used in 75 cases (30.1\%) and activated charcoal in 18 (7.2\%). Nintey-five children (38.2\%) were admitted to the pediatric department, but no complications occurred. Targeted information programs in schools and during pediatric check-ups should decrease the risk of ingestion of non-pharmacological substances in children, and the costs of its management.

Key words: intoxication, poisoning, child

\section{Introduction}

Intoxications and poisonings in children are related to the accidental ingestion of a toxic substance with potential life-threatening consequences. In Italy $84 \%$ of intoxications involve children under 5 years of age (pre-school age), with a peak around 2 years, (1-3) 10\% involve children between 5 and 9 years of age, and $6 \%$ children older than 9. The majority (80-90\% of total) of these ingestions occur in the domestic environment. (4) According to the Global Burden of Diseases Study 2010, which assessed the distribution of mortality in children from o to 17 years by violent causes, the category "intoxication and poisoning", is set at $3.9 \%$. (5) Prompted by poor epidemiological data on intoxications and poisonings in Italian children, we studied all cases of acute intoxications and poisonings, from non-pharmacological substances, in children admitted between $1^{\text {st }}$ January 2001 and $31^{\text {st }}$ December 2012 to the Emergency Room of our University in Rome. We disregarded cases related to pharmacological substances or foreign body ingestions. Our effort represents the first step to carry out further studies to outline the frequency and distribution of cases, obtain demographic data of these patients, clarify the size and features of the sample, and evaluate the opportunity of launching targeted programs of prevention activities and health education.

\section{Patients and methods}


This observational-descriptive study was carried out in collaboration with the Institute of Pediatrics, the Poisons Center, and the Pediatric Intensive Care Unit of our University in Rome. For the purposes of this retrospective study we enrolled all patients aged between $\mathrm{o}$ and 14 years who arrived at the Emergency Room for acute intoxication or poisoning from non-pharmacological substances during the period $1^{\text {st }}$ January 2001 to $31^{\text {st }}$ December 2012. All data collected (age, sex, time and date of admission to the Emergency Room, type of substance ingested, symptoms manifested, laboratory tests conducted, consultations required, therapies, outcome and eventual hospitalization needed) were placed in a singular electronic database.

\section{Results}

During the 12 year period, a total of 249 patients satisfied the inclusion criteria : 147 males (59\%) and 102 females (41\%). Twenty patients (8.1\%) experienced an episode of poisoning from non-pharmacological substances during the first year of life (o-1 year). A much larger share, consisting of 110 children ( $44.2 \%$ of the sample), was represented by children aged 1-2 years (peak incidence), followed by 47 cases (18.9\%) between 2 and 3 years. The incidence began to decrease in the range between 3 and 4 years (27 children, 10.8\%), and this decline became more evident in the evaluation of later periods: 28 children (11.2\%) between ages 4 and 6, 7 children (2.8\%) between 6 and 8, 4 patients (1.6\%) between 8 and 10 years and an equal percentage (3 cases, 1.2\%) respectively for children from 10 to 12 years and for those from 12 to 14 years. Considering the time of arrival to the Emergency Room, using a stratification of 3 hour time slots, two peaks of incidence were highlighted: from 12:00 to 15:00 (54 patients, $21.7 \%$ of total) and from 18:00 to 21:00 (59 cases, $23.7 \%$ ). To evaluate a possible relationship between intoxication and seasonality, we also considered the month of presentation to the Emergency Room. The months with more admissions were June (35 cases, $14 \%$ of the sample) and October (33 cases, 13.2\%). Grouping according to seasons, in order of decreasing incidence, showed that 73 cases (29.3\%) occurred in spring, 64 cases (25.7\%) in autumn, 59 
cases $(23.7 \%)$ in winter and $53(21.3 \%)$ in summer.

As reported in table 1, several non-pharmacological toxic substances had come into contact with the 249 patients in our sample. It was possible to place every toxic substance in a specific category, allowing us to establish an order of incidence for each class (figure 1, table 2).

The solvents were absolutely the most frequently involved substances (111 cases, 44.6\%). In this category products for home cleaning (56 cases, 22.5\%) deserved special attention. More specifically, detergents, considered singularly, were the products that had attracted the most attention in children (39 cases, $15.6 \%$ of the total), followed by cosmetics and products for personal hygiene (soaps, shampoos, perfumes, colognes, creams, acetone: 22 cases, 8.9\%), then alcohol (ethyl alcohol in the form of wine, beer, spirits, disinfectants containing alcohol; 17 cases in total, $6.8 \%)$.

Natural products were responsible for 44 cases (17.7\%). Of this set, the frequency of poisoning from toxic plants and derivatives (berries, leaves, seeds: 22 cases, 8.9\%) prevailed, followed by cases of ingestion of parts of cigarettes (16 cases, 6.4\%), while the remaining were attributed to the ingestion of potentially poisonous mushrooms (4 cases, 1.6\%) and animal substances (feces of dogs and dog food: 2 cases, $0.8 \%$ ).

Products used in agriculture were responsible for 32 cases (12.9\%).

Rodenticides and insecticides prevailed, respectively with 13 (5.3\%) and 10 (4\%) cases, while 3 (1.2\%) were related to other substances.

Corrosive acids and caustic alkaline products (ammonia, caustic soda, bleach) were implicated in 37 cases (14.8\%): diluted bleach and concentrated bleach were involved respectively in 8 (3.2\%) and 7 cases (2.8\%) of poisoning, while a lower frequency was reported for anti-lime scale acids and descaling products ( 5 cases for both, $2 \%$ ).

Low frequencies were recorded for the set of glues/adhesives/paints/inks ( 9 cases, 3.6\% of the total) and for metals (9 cases, 3.6\%): with regard to the latter category it was necessary to emphasize the absolute predominance of ingestion of liquid mercury, usually taken by children following the breaking of old thermometers (8 cases out of 9: $3.2 \%$ ). 
Only 2 cases ( $0.8 \%$ of the total) of gas poisoning and toxic vapors were registered.

To conclude, over the 12 years of investigation, in only 5 cases ( $2 \%$ of total) was it not possible, to determine the substance causing the suspected intoxication.

Among the 249 children in the sample, 116 (46.6\% of the total) showed no clinical symptoms and physical examination was completely normal. Among the remaining 133 children, the most frequently occurring symptoms were nausea and vomiting ( 55 cases, 22\%). Also the finding of pharyngeal hyperemia (47 children, 18.8\%) was very frequent, but this was a nonspecific sign. Then, a smaller percentage of children (12 to 18 cases, from $4.8 \%$ to $7.2 \%$ of total) experienced symptoms like abdominal pain, pain during swallowing, sore throat and cough. With similar percentages (5.6\% of cases), 14 children were found to have a smell and/or traces of toxic substances in the oral cavity or on the skin. Less frequent symptoms were burning of the mouth, hyperemia and/or burning of the skin (both in 9 patients, 3.6\%), fever (8 patients, 3.2\%), oral lesions (hemorrhagic or necrotic, in 7 children, 2.8\%); diarrhea, drooling and tongue dysepitheliazation (each present in 6 cases, 2.4\%), numbness and/or drowsiness, hyporeactivity, conjunctival hyperemia, cold sweating. and respiratory complications (in 3-5 children, $1.2-2 \%$ of the total). Other rare symptoms developed once or at most twice in the whole sample, including restlessness and agitation, peripheral subcyanosis, spasm of the glottis, bronchospasm, edema of the eyelids associated with lacrimation, miosis, irritation and erythema of the tongue or lips, mouth edema, disturbances of language, heartburn, intense belching, nose bleeding, dizziness, polyuria, periorbital and facial petechiae.

In the Emergency Room of our University, laboratory tests and imaging studies were performed in selected cases, while specific toxicological examinations were never done. Regarding laboratory tests (figure 2), routine parameters were required in about 50 cases ( $20 \%$ of the total), with slight variations due to pediatricians' decisions. Blood clotting tests were performed in a smaller number of cases (29 patients, 11.6\%), whereas blood gas analysis in 9 patients (3.6\%). Also instrumental 
examinations and diagnostic imaging (figure 3) were carried out in symptomatic patients. Electrocardiogram and chest X-ray were frequently performed (respectively, in 15 and 13 children, or 6\% and $5.2 \%)$. Esophagogastroduodenoscopy was necessary in 5 patients (2\%). Abdominal X-ray and urinalysis were both required in 3 children $(1.2 \%$ of the total).

In terms of consulting requests, the Poisons Center was contacted 156 times (62.6\% of cases), the Pediatric Intensive Care Unit 38 times, (15.2\%), while particular situations prompted for the following specialist advice: surgeon-endoscopist (18 patients, 7.2\%), ENT (2 patients, $0.2 \%$ ), and ophthalmologist (1 patient).

Completely asymptomatic patients were discharged from the Emergency Room immediately after the visit, while for the others (106 patients, $42.5 \%$ of the total) a short period (1-2 hours on average) of observation and monitoring was indicated, during which, for some of these symptomatic children, therapeutic options were explored (figure 4). Regarding drug therapy, the administration of gastroprotective drugs (75 cases, 30.1\%) was the most frequent choice in the Emergency Room. Activated charcoal (in single or multiple doses) was used in 18 patients (7.2\%), usually due to advice received by the Poisons Center, while 11 patients (4.4\%) benefited from the administration of dimethicone. It is necessary to report, in addition, the administration of milk and similar products (such as yogurt) in 25 children (10\%). Among the most invasive measures, fluid therapy was started in 28 patients (11.2\%), while gastrolusis was performed in 7 (2.8\%).

Of the 249 patients, 154 (61.8\%) children were discharged directly from the Emergency Department, while 95 (38.2\%) required hospitalization. Among these 95 patients who needed admission to the hospital, the majority (75 cases, $30.1 \%$ of the total sample) was admitted to the Pediatric ward. In the end, there were 16 admissions (6.5\% of total) to the Division of Pediatric Surgery, while only 4 children (1.6\%) required assistance in the Pediatric Intensive Care Unit. No complications occurred. No deaths due to poisoning from non-pharmacological substances were recorded. 


\section{Discussion}

With regards to the relationship between intoxication and age of patients, as with data from several scientific studies in the medical literature, (6) in our study the highest incidence occurred in the first 4 years of life, with an extremely important peak in patients between 1 and 2 years (figures 5 , 6). These adverse events occurred accidentally in the group between 1 and 3 years: (7) this may be closely related to the so-called "oral phase" of the psycho-emotional development of children, in conjunction with an improper or careless storage of toxic products by parents or whoever is supervising the child. By 5 years of age, children outgrow this exploratory oral phase and in fact the number of episodes of acute poisoning becomes less frequent. In adolescents, on the other hand, intentional poisonings begin to predominate. (8) In fact, the voluntariness is more frequent from pre-adolescence (10-14 years) onwards, with a prevalence in females, especially to demonstrate a specific discomfort rather than selfharming. (9) Also noteworthy is the possibility that certain toxic accidents occur as real expressions of child abuse: especially for children under 5 years of age, the possibility of Münchausen syndrome by proxy is in fact mentioned. (10)

Regarding the most at-risk periods of the day, it is appropriate to expect an increase in poisonings during the time slots between 11.00 and 14.00 and especially between 18.00 and 22.00, when parents tend to be particularly distracted by housework or simply tired after a working day. On the contrary, there was an evident fall in the number of cases of acute poisonings occurring in the night. The number of cases occurred in the morning was also low, probably due to general commitments of children, such as school activities. To confirm this, we focused attention only on the summer months and found, there was an inversion of frequency, with the greatest peak reached in the morning, between 11.00 and 14.00. Moreover, in regard to the relationship between poisoning and the month of the year in which toxic events occurred, in our series (figure 7) the data from the medical literature (2) were not confirmed, according to which there is a greater number of poisonings during summer months; on the contrary, our study showed the lowest number of cases precisely in the summer months (21.3\%, 53 cases). 
In our series a large percentage of symptomatic children presented clinical manifestations (especially nausea, vomiting and abdominal pain) following ingestion of household detergents (39 cases: 15,6\%) and similar derivatives (cosmetics and products for personal hygiene, disinfectants, petroleum and derivatives, preservatives for clothing, etc.), which are often signaled in the literature as basically harmless. $(11,12)$ Other substances that frequently caused the appearance of signs and symptoms proved to be "dangerous", according to data collected in the records of our University, were tobacco and nicotine contained inside ingested cigarettes, plants, acid and caustic alkaline substances (bleach, ammonia), various solvents (acetone, turpentine), insecticides and pesticides, petroleum derivatives, descaling and drain unblockers. The "non-dangerousness" of several substances, however, is debtable, because any type of product, if ingested or inhaled in large quantities or high concentrations, can become harmful and even potentially lethal.

As far as symptoms are concerned (figure 8), the most important variable to be analyzed was the age of the patients. The severity of symptoms paradoxically grew proportionally to the age of children. This outcome can be correlated with children's capacity of ingestion, obviously higher in pre-teens. Younger children also fail to ingest significant doses because they are fortunately held back by the bad taste. Almost half of the sample in our study (116 patients, 46.6\%) was totally asymptomatic, and this information was probably underestimated, given the fact that among patients classified as symptomatic there were some who experienced just pharyngeal hyperemia, or tonsillar hypertrophy, or even a slight rise in temperature, all absolutely nonspecific signs and not simply related to the ingestion of a toxic substance. Symptoms more realistically indicating a poisoning episode were: vomiting and nausea (symptoms presented by more than one fifth of the total sample), abdominal pain (expressed as stomach pain), sore throat and odynophagia, and finally cough (following tracheal irritation). Other symptoms occurred with much lower incidences.

Laboratory tests most frequently requested in the Emergency Room were reported in figure 2: most of these were absolutely normal. During the 12 year observation period, arterial blood gases were indicated only in 
clearly symptomatic patients, but no child ever manifested signs and symptoms of acidosis or alkalosis. Among instrumental tests (figure 3), the electrocardiogram was required in cases of ingestion of pieces of cigarettes and pesticide intoxication. Chest radiography was necessary in the ingestion of dangerous toxics (such as caustic acids) and in cases of poisoning with severe respiratory symptoms. The few esophagogastroduodenoscopies performed in the 12 year period followed the ingestion of potentially very harmful agents, such as anti-limestone and caustic acids.

In regard to consultations, as analyzed in figure 9, in our cases, calls to the Poisons Center predominated, followed by the Pediatric Intensive Care Unit. In the most hazardous cases, the expert of the Poisons Center usually indicated which therapeutic measures should be undertaken for the individual patient examined. Gastrolusis, as a decontamination technique, is only recommended if highly toxic or large amounts of harmful substances are ingested, mostly if the substance is not absorbable by activated charcoal. There is controversy in the medical literature regarding the administration of milk and similar products (especially yogurt), although it is prohibited for systematic use in all types of acute poisoning, milk and similar products can be administered to intoxicated children exclusively on the advice of an expert toxicologist, after having assessed the presence of specific indications (such as ingestions of caustic substances).

Finally, about 95 children (38.2\%) were hospitalized in the Division of Pediatrics (First Infancy) (figure 10): this was a direct consequence of most intoxicated children's age, which was around 1-2 years. Hospitalization in the Pediatric Intensive Care Unit was necessary only for 4 children.

\section{Conclusions}

The majority of acute poisonings in children (about 80-90\%) occur when children are at home. Unfortunately, a fleeting distraction of adults can be sufficient to induce babies to explore and try out new things. (13) The lack of preventive measures is the major risk factor for acute poisoning in 
children and prevention measures remain the first and most effective strategy. Even now, in the Emergency Room, establishing clearly-defined or widely-shared treatment guidelines remains difficult, due to different variables (age, amount of substance ingested, degree of toxicity, toxicokinetics and toxicodynamics, time elapsed from exposure, child's clinical condition). So it would be crucial to establish a uniform therapeutic protocol to manage ingestions of toxic substances. (14) A standardized and easily applicable model to define the severity of intoxication and poisoning would allow a qualitative evaluation of symptoms and comparison of data across multiple centers. (15) The institution of a few beds for Pediatric Short Observation in the same Emergency Room, to intercept the possible appearance of symptoms after a latency period, might also be advantageous. Over the last decade, public health institutions have focused their attention on these accidents with increasing interest. Thanks to prevention programs, at least in industrialized countries, the number of cases of acute intoxication and poisoning in children is significantly decreasing, although their economic costs remain high. (16) It might be useful to create appropriate interventions and targeted information campaigns in schools, while parents and caregivers should be continually updated by experts through the promotion of prevention of intoxications and poisonings, which might become an integral part of all pediatric check-up visits.

\section{References}

1. Christesen HB. Epidemiology and prevention of caustic ingestion in children. Acta Paediatr 1994;83:212-5.

2. Vilke GM, Douglas DJ, Shipp H, Stepanski B, Smith A, Ray LU, Castillo EM. Pediatric poisonings in children younger than five years responded to by paramedics. J Emerg Med 2011;41:265-9.

3. Hoikka M, Liisanantti J, Dunder T. Acute poisoning in children under the age of six: a two-decade study of hospital admissions and trends. Acta Paediatr 2013;102:e329-33.

4. Riffat F, Cheng A. Pediatric caustic ingestion: 50 consecutive cases and a review of the literature. Dis Esophagus 2009;22:89-94.

5. Lozano R, Naghavi M, Foreman K, Lim S, Shibuya K, Aboyans V, et al. 
Global and regional mortality from 235 causes of death for 20 age groups in 1990 and 2010: a systematic analysis for the Global Burden of Disease Study 2010. Lancet 2012;380:2095-128.

6. Kliegman R, Behrman R, Jenson H, Stanton B. Saunders-Elsevier, Nelson Textbook of Pediatrics. Philadelphia, volume I, part VII, 2007.

7. Barelli A, Botti P, Della Puppa T. TBST (Toxicological Basic Support and Therapy) - Argomenti di tossicologia clinica d'urgenza. Italian Resuscitation Council, Bologna, 2008.

8. Arévalo-Silva C, Eliashar R, Wohlgelernter J, Elidan J, Gross M. Ingestion of caustic substances: a 15-year experience. Laryngoscope 2006;116:1422-6.

9. Neilson ZE, Morrison W. Childhood self-poisoning: a one-year review. Scott Med J 2012;57:196-9.

10. Dinis-Oliveira RJ, Magalhães T. Children intoxications: what is abuse and what is not abuse. Trauma Violence Abuse 2013;14:113-32.

11. Goulding R. Poisoning. Blackwell Scientific Publications, London, 1990.

12. Meyer S, Eddleston M, Bailey B, Desel H, Gottschling S, Gortner L. Unintentional household poisoning in children. Klin Padiatr 2007;219:254-70.

13. Assisi F, Moro P, De Tollis A. Epidemiologia delle intossicazioni acute in pediatria. Centro Antiveleni di Milano, 1998.

14. Karagiozoglou-Lampoudi T, Agakidis $\mathrm{CH}$, Chryssostomidou S, Arvanitidis K, Tsepis K. Conservative management of caustic substance ingestion in a pediatric department setting, short-term and long-term outcome. Dis Esophagus 2011;24:86-91.

15. Barelli A, Biondi I, Tafani C, Pellegrini A, Soave M, Gaspari R, Annetta MG. A relational database to store Poison Centers calls. Ann Ist Super Sanità 2006;42:310-7.

16. De Jong AL, Macdonald R, Ein S, Forte V, Turner A. Corrosive esophagitis in children: a 30-year review. Int J Pediatr Otorhinolaryngol 2001;57:203-11.

Table 1. Partition of various toxic non-pharmacological substances found in the clinical records of children evaluated in our University during a 12-year-period. 
SOLVENTS halogenated

aliphatic

hydrocarbons

aromatic

hydrocarbons white spirit,

trichlorethylene or trieline,

methyl chloride or

chloromethane,

chloroform or freon 20 ,

carbon tetrachloride or freon 10 ,

oil (and its derivatives, including tablets),

benzene or gasoline,

toluene,

xylene,

styrene,

alcohols

ethyl alcohol (wine, beer, spirits, super-alcoholic drinks),

methanol, isopropanol,

disinfectants,

glycols

ethylene glycol or antifreeze,

diethylene glycol,

cleaning products detergents,

soaps,

softeners,

spottings,

degreasers,

preservatives for shoes or clothing,

specific products to clean glass, 
steel, silver, wood and other

metals,

cosmetics and

products for

personal hygiene

acetone,

various detergents (soap, shampoo, shower gel, spray),

scented oil and suntan lotions,

creams and body lotions,

non-alcoholic deodorants,

shaving foam,

toothpaste

CAUSTIC ACID PRODUCTS

hydrochloric acid, nitric acid, boric acid, muriatic acid,

sulfuric acid or vitriol,

sodium hypochlorite or bleach or antiseptic (at different dilutions),

anti-crust and anti-limestone for sinks and toilet

CAUSTIC ALKALINE PRODUCTS ammonia (also present in detergents, softeners and stain removers),

caustic soda or sodium hydroxide,

potassium hydroxide,

sodium carbonate,

potassium carbonate,

GLUES, ADHESIVES, PAINTS and INKS

AGRICULTURE PRODUCTS pesticides,

organophosphate insecticides, rodenticides (warfarinics), 
herbicides,

manure and fertilizer,

mothballs (camphor,

naphthalene, dichlorobenzene)

NATURAL toxic plants PRODUCTS

(n)

leaves of the tobacco plant (with nicotine),

house plants (leaves of oleander, Christmas Star),

grass and garden plants,

belladonna berries,

holly berries,

laurel berries,

honeysuckle berries,

asparagine berries,

wild iris berries,

tea powder,

animal substances dog food,

dog excrement,

toxic mushrooms amanita muscaria,

amanita phalloides,

boletus satanas,

TOXIC GAS and FUMES

carbon monoxide,

carbon dioxide,

oxygen at high concentrations,

nitrogen,

ethane, 
methane,

argon,

helium,

chlorine,

hydrochloric acid,

hydrogen cyanide,

nitrogen monoxide,

nitrogen dioxide,

tear gas and pepper spray

METALS

mercury in the thermometer,

lead, aluminum, gold, silver,

cadmium, tin, arsenic,

chrome, beryllium, nickel

UNKNOWN SUBSTANCES

Table 2. List of various toxic non-pharmacological substance categories, ordered from the most frequent to the least, in children evaluated in our University during a 12-year-period.

Substance type

various solvents

natural products

products for

agriculture

corrosive acids

glues, paints and inks

\section{Absolute frequency and percentages}

111 cases, $44,6 \%$

44 cases, $17,7 \%$

32 cases, $12,9 \%$

30 cases, $12,0 \%$

9 cases, $3,6 \%$ 
metals

9 cases, 3,6\%

caustic alkaline

products

7 cases, $2,8 \%$

undetermined

substances

5 cases, $2,0 \%$

toxic gas and vapors $\quad 2$ cases, $0,8 \%$

Figure 1. Pie chart showing the percentage distribution of all categories of identified substances in the clinical records of children evaluated in our University during a 12-year-period.

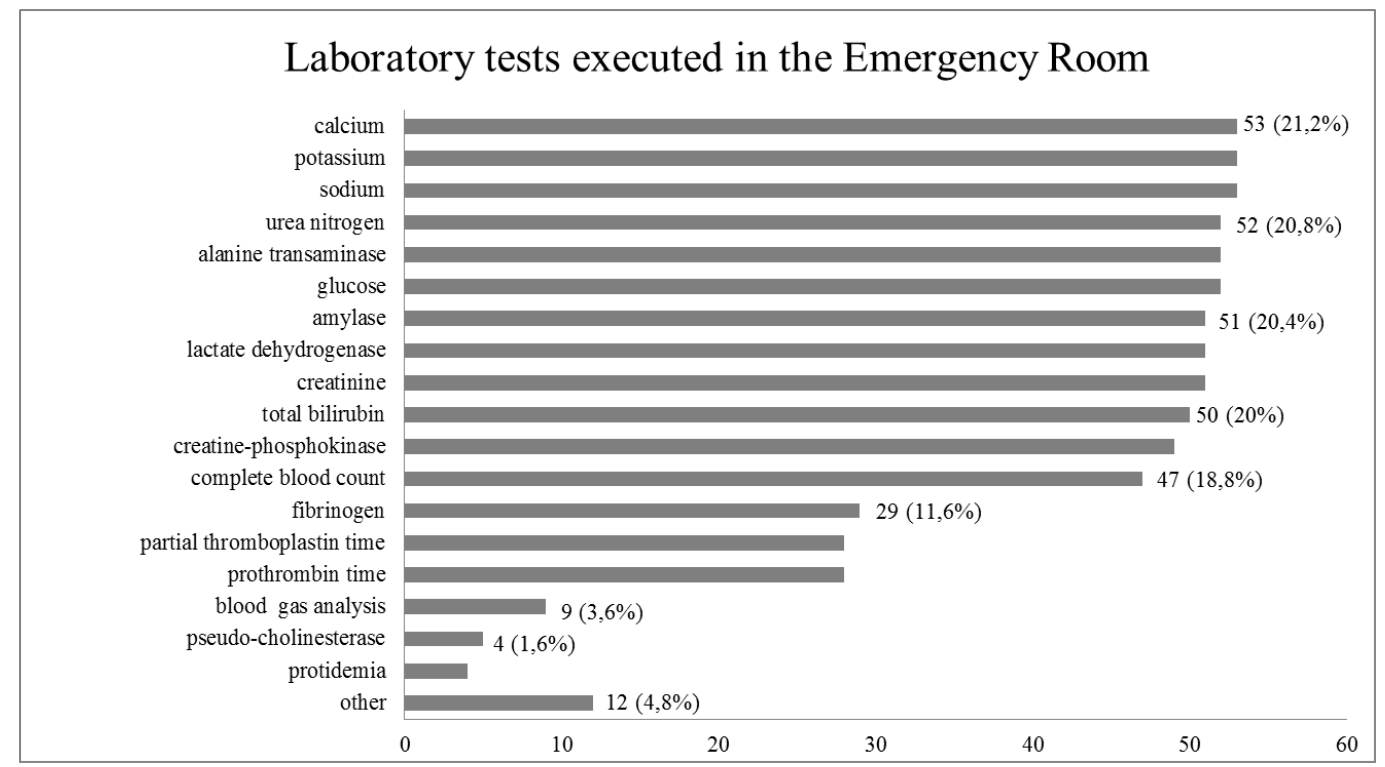

Figure 2. Bar graph showing the most frequent ordered laboratory tests in the Emergency Room for cases of ingestion of non-pharmacological substances.

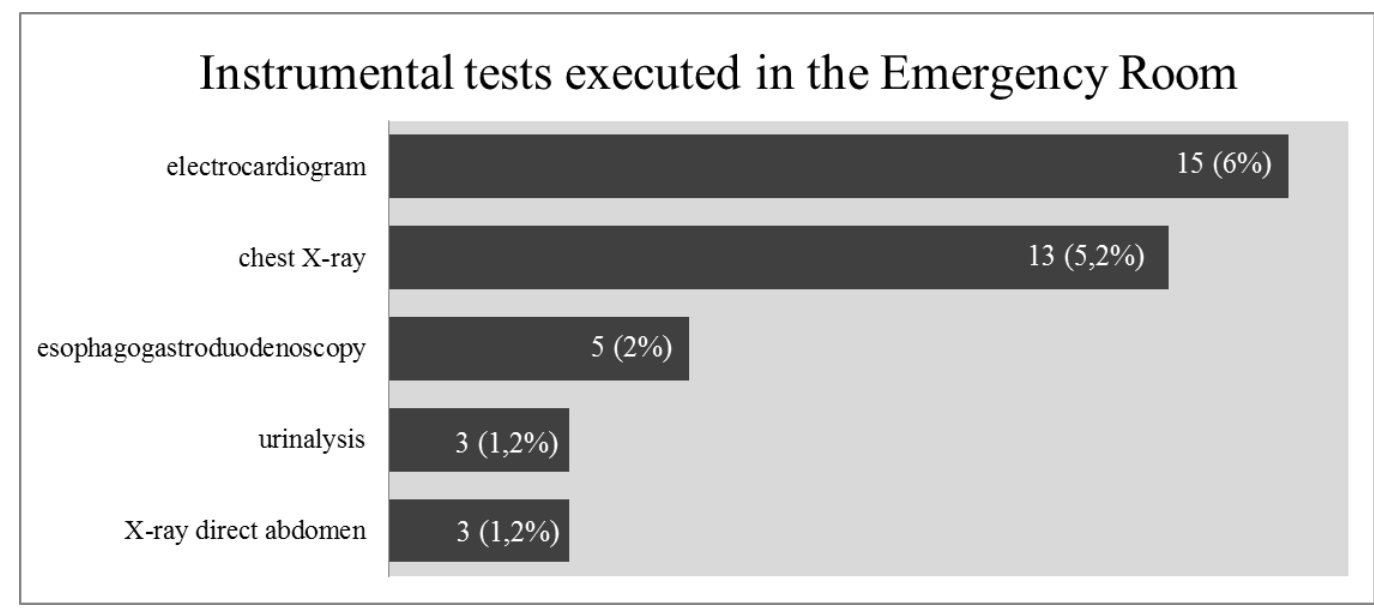


Figure 3. Bar graph showing the frequency of instrumental tests and examinations for diagnostic imaging required in the Emergency Room for cases of ingestion of non-pharmacological substances.

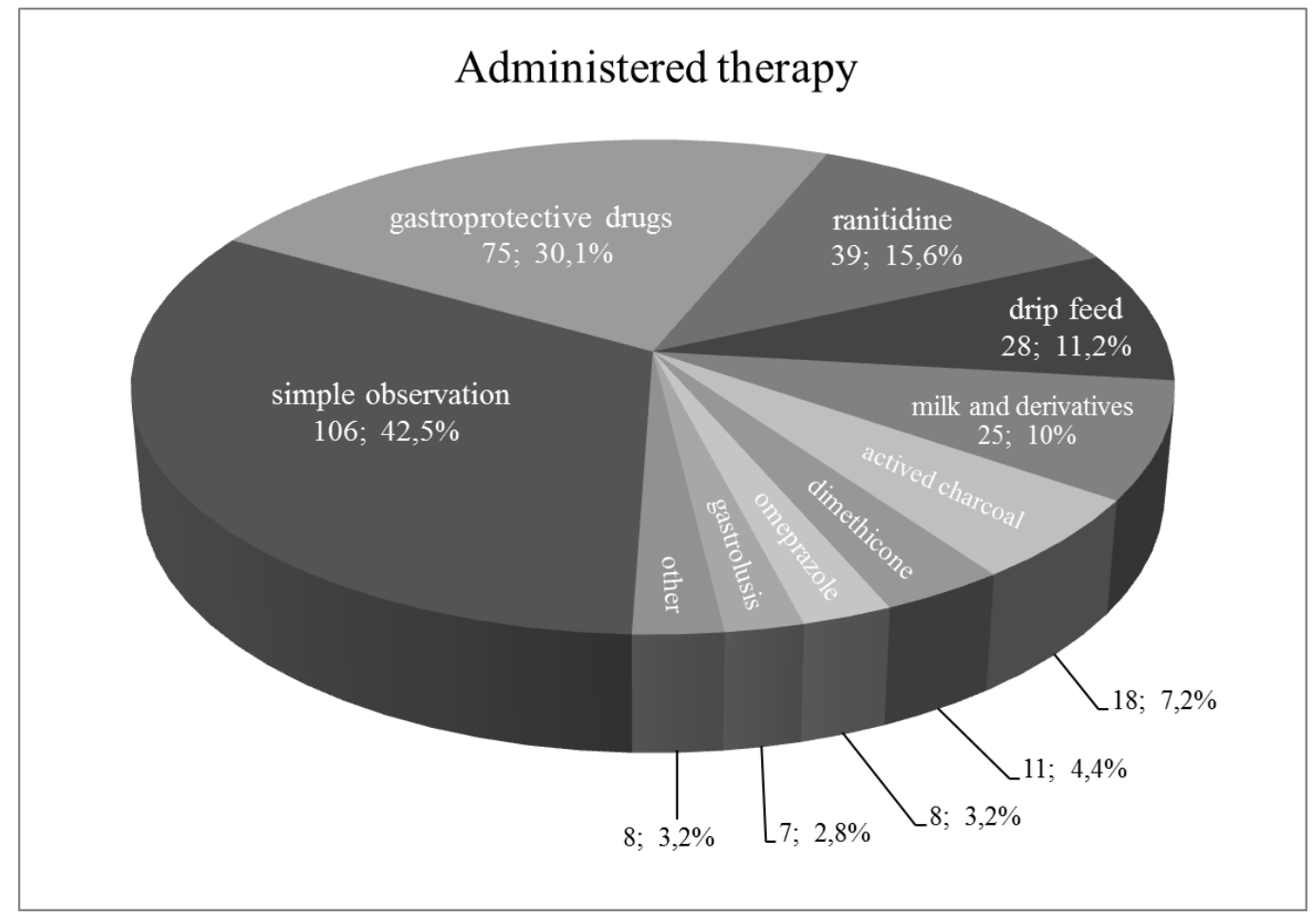

Figure 4. Pie chart showing the distribution of various types of therapies used in the Emergency Room for intoxicated children.

\section{Age of children at time of intoxication}

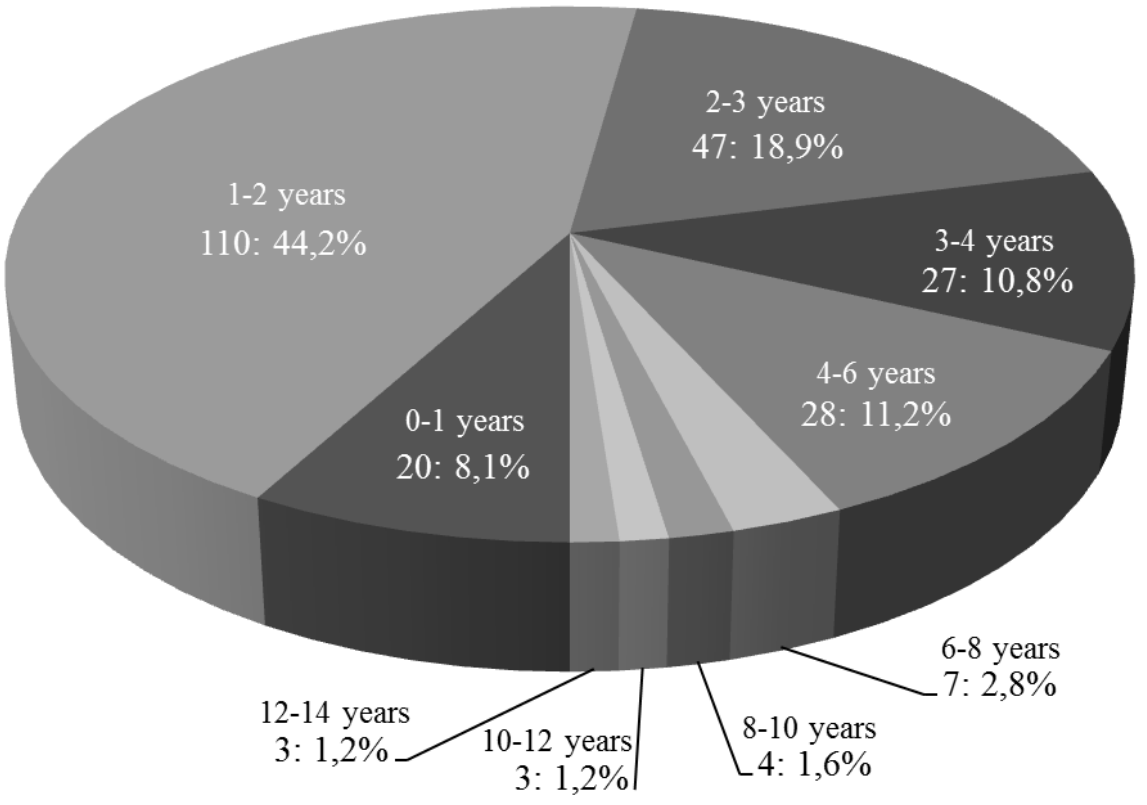

Figure 5. Distribution of the sample in a pie chart based on the age of 
children at the time of intoxication/poisoning.

Figure 6. Line graph showing the variations in the incidence of acute intoxication or poisoning in the various pediatric age groups.

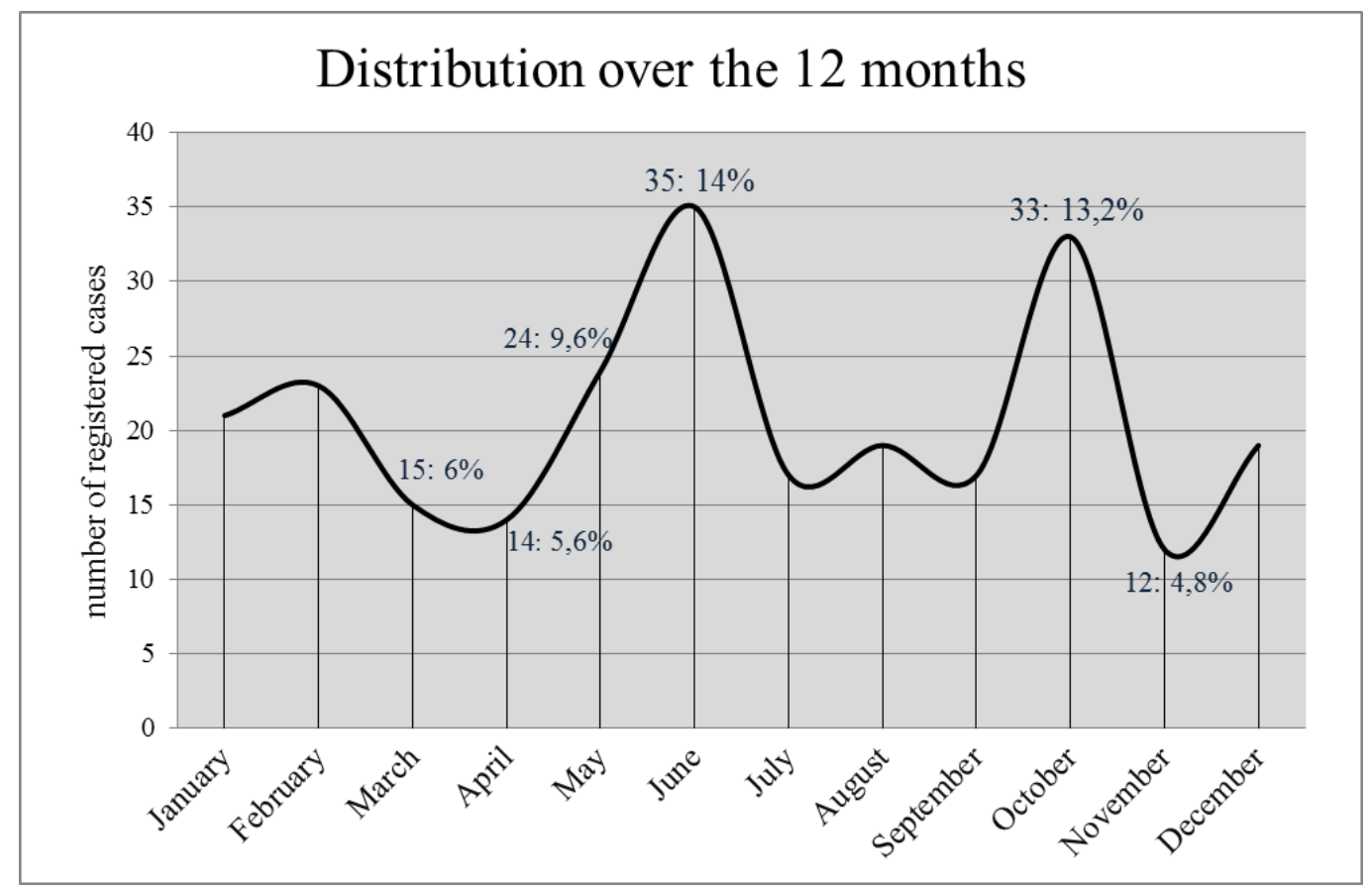

Figure 7. Distribution of acute intoxications and poisonings over the 12 months of the year.

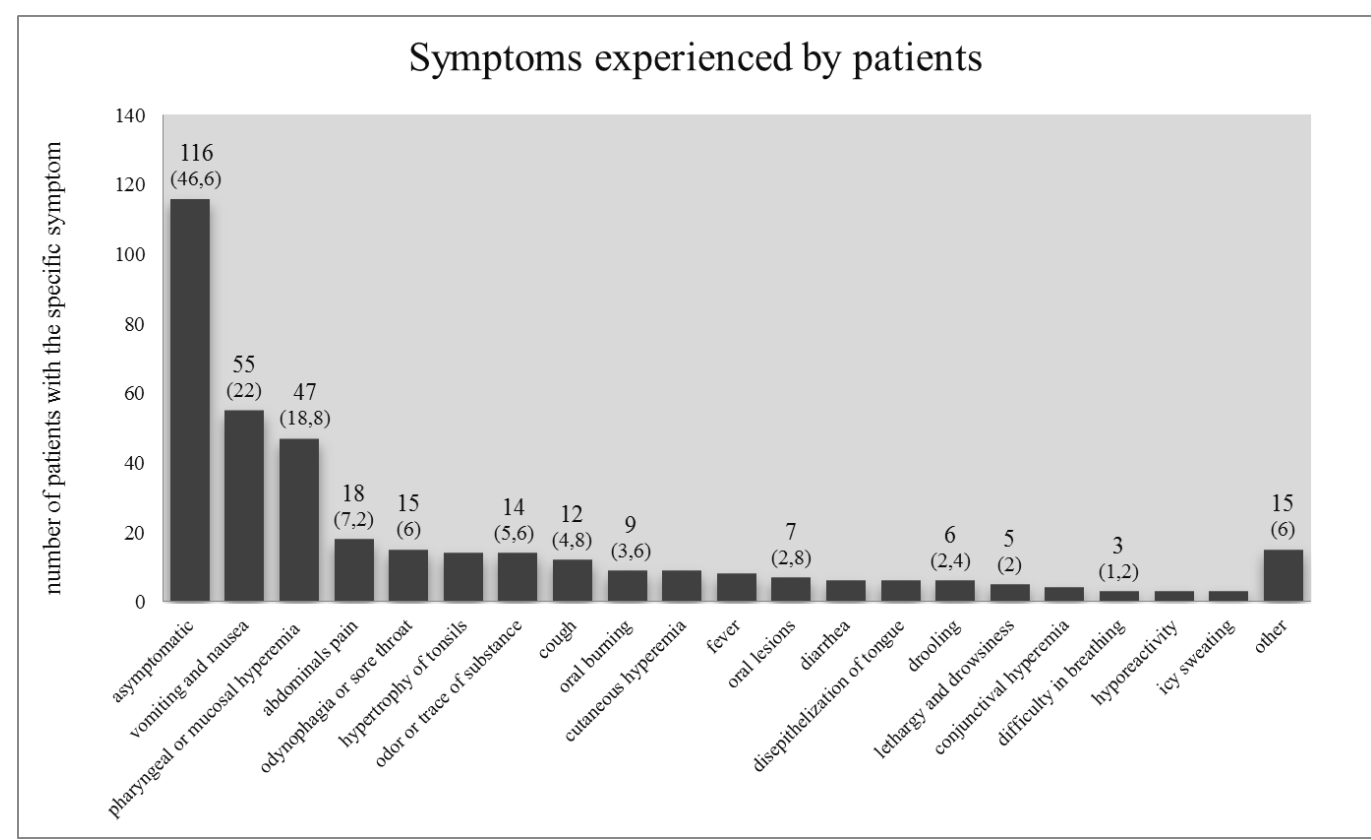

Figure 8. Bar graph showing the number of asymptomatic patients and the incidence of the various symptoms manifested by symptomatic children (the percentage of patients is in the brackets). 


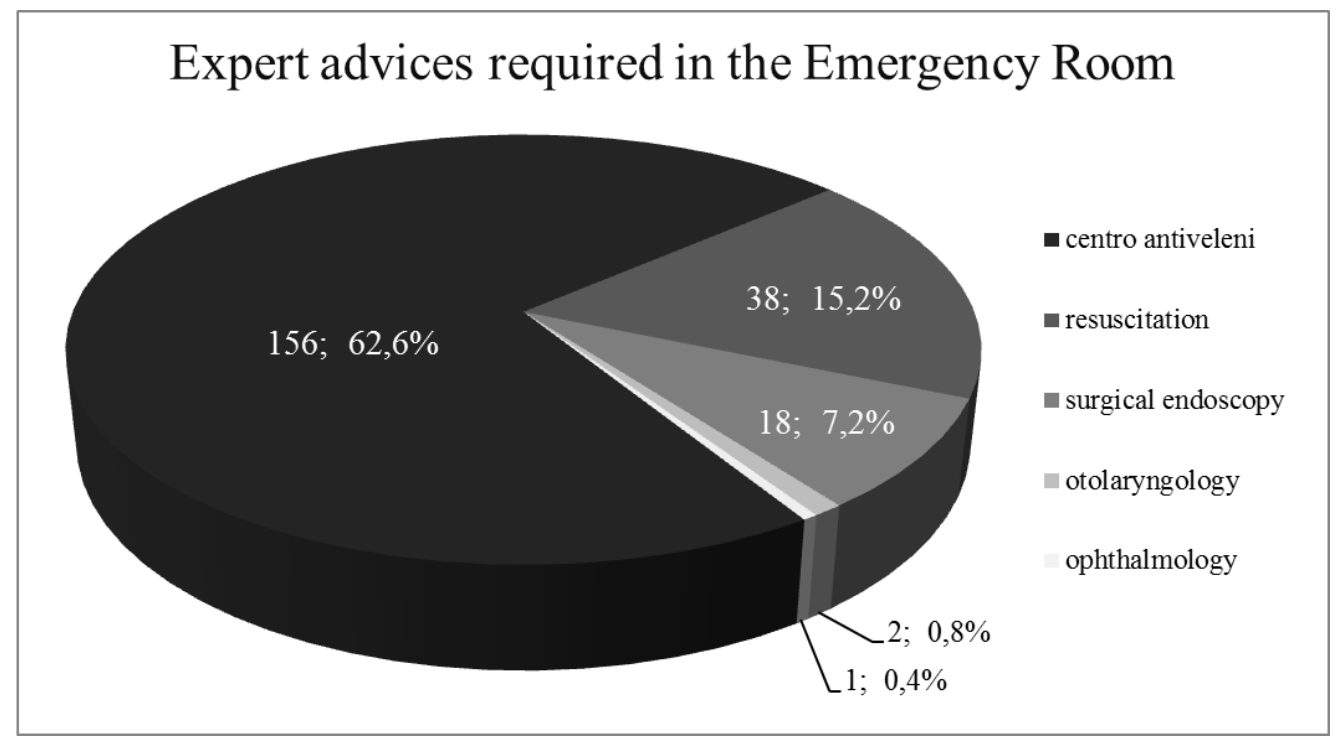

Figure 9. Pie chart with the distribution of the number and type of expert advice required during the visit of intoxicated children in the Emergency Room.

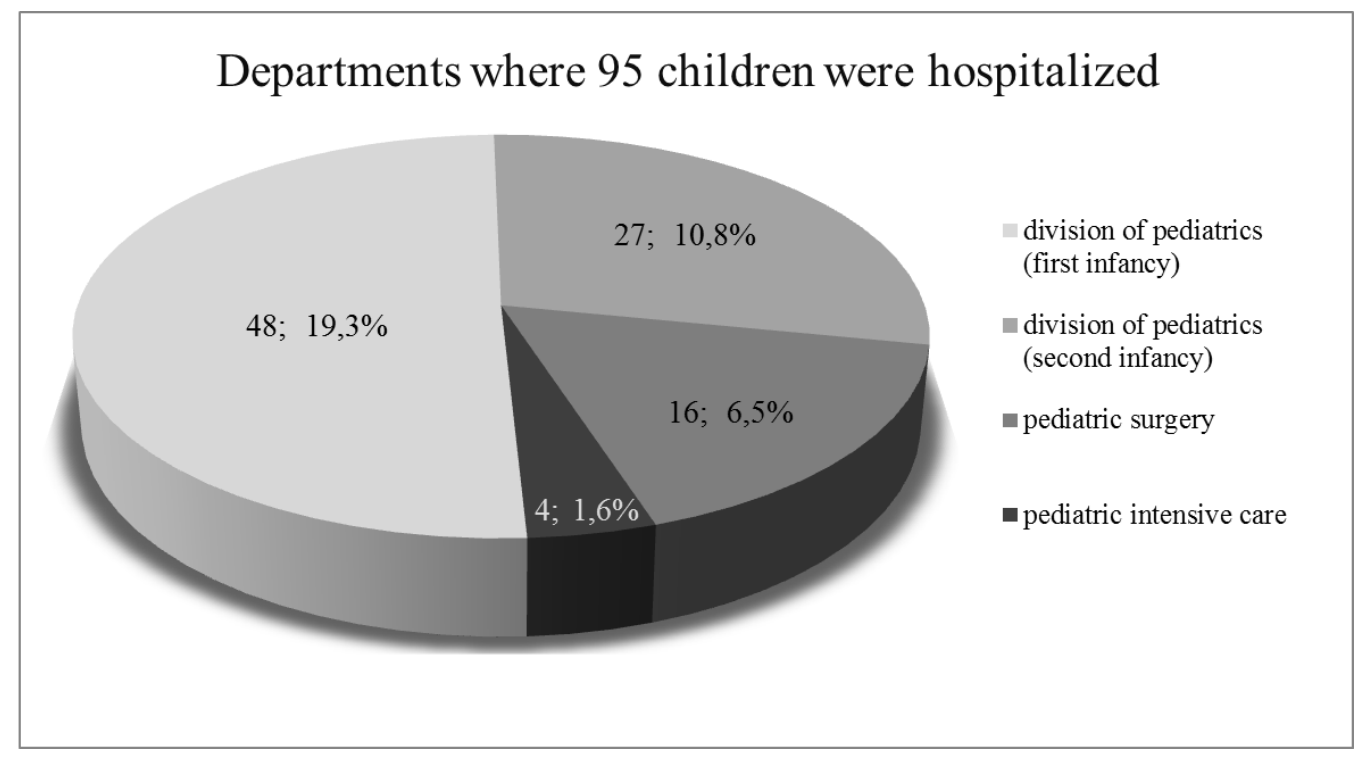

Figure 10. Pie chart showing in detail the pediatric departments to which 95 children (38.2\%) requiring hospitalization were entrusted.

Corresponding author:

Luca Tortorolo

Pediatric Intensive Care Unit

Università Cattolica Sacro Cuore

Largo Gemelli 800168 Rome, Italy

Phone: +39.06.30155203

Fax: +39.06.3383211

E-mail: luca.tortorolo@gmail.com 
Article printed from Signa Vitae: http://www.signavitae.com

URL to article: http://www.signavitae.com/2015/12/acuteintoxication-and-poisoning-in-children-the-experience-of-atertiary-care-hospital-from-2001-2012/

Copyright (C) 2015 Signa Vitae. All rights reserved. 